\title{
GLYCOLYSIS IN CONTRACTING RAT SKELETAL MUSCLE IS CONTROLLED BY FACTORS RELATED TO ENERGY STATE
}

\section{Niels ØRTENBLAD* ${ }^{1}$, Will A. MACDONALD ${ }^{\dagger}$ and Kent SAHLIN ${ }^{*}, \star \S$}

*Institute of Sports Science and Clinical Biomechanics, University of Southern Denmark, DK-5620 Odense, Denmark, 'Institute of Physiology and Biophysics, University of Aarhus, DK-8000 Århus, Denmark, ${ }^{\dagger}$ The Swedish School of Sport and Health Sciences, Box 5626, S11486 Stockholm, Sweden Sweden, and ${ }^{\S}$ Department of Physiology and Pharmacology, Karolinska Institute, Box 5626, S-114 86 Stockholm, Sweden.

Short title: Activation of skeletal muscle glycolysis

${ }^{1}$ To whom correspondence should be addressed (email: nortenblad@health.sdu.dk)

Keywords: Skeletal muscle, Glycogenolysis, Glycolysis, Energy turnover, N-Benzyl-ptoluene sulphonamide

The abbreviations used are: BTS, $N$-benzyl-p-toluene sulfonamide; Con, control muscle; SR, sarcoplasmic reticulum; MRS, magnetic resonance spectroscopy; EDL, extensor digitorum longus; KR, Krebs-Ringer bicarbonate buffer; Lac, lactate; PCr, phosphocreatine; $\mathrm{Cr}$, creatine; G-1-P, glucose 1-phosphate; G-6-P, glucose 6-phosphate; F-6-P, fructose 6phosphate; Pyr, pyruvate; GI, Glycolytic intermediates; $\Delta$ refers to the difference between metabolite concentration in the stimulated muscle and the contralateral resting muscle; $\mathrm{pH}_{\mathrm{m}}$, Muscle $\mathrm{pH}$. 
BJ2008/2135, Activation of skeletal muscle glycolysis

\section{SYNOPSIS}

The control of glycolysis in contracting muscle is not fully understood. The aim of the present study was to examine whether activation of glycolysis is mediated by factors related to energy state or by a direct effect of $\mathrm{Ca}^{2+}$ on the regulating enzymes. Extensor digitorum longus muscles from rat were isolated, treated with cyanide to inhibit aerobic ATP production and stimulated ( $0.2 \mathrm{~s}$ trains every $4 \mathrm{~s})$ until force was reduced to $70 \%$ of initial force (Con). Muscles treated with BTS, an inhibitor of cross-bridge cycling without affecting $\mathrm{Ca}^{2+}$ transients, were stimulated for an equal time as Con. Energy utilization by the contractile apparatus (estimated from the observed relation between ATP utilization and force-time integral) was $60 \%$ of total. In BTS force-time integral and ATP utilization was only $38 \%$ and $58 \%$ of that in Con, respectively. Glycolytic rate in BTS was only $51 \%$ of that in Con but the relative contribution of ATP derived from $\mathrm{PCr}$ and glycolysis and the relation between muscle contents of $\mathrm{PCr}$ and lactate were not different. Prolonged cyanide incubation of quiescent muscle (low $\mathrm{Ca}^{2+}$ ), did not change the relation between $\mathrm{PCr}$ and lactate. The reduced glycolytic rate in BTS despite maintained $\mathrm{Ca}^{2+}$ transients, and the unchanged PCr/Lactate relation in the absence of $\mathrm{Ca}^{2+}$ transients, demonstrates that $\mathrm{Ca}^{2+}$ is not the main trigger of glycogenolysis. Instead the preserved relative contribution of energy delivered from PCr and glycolysis during both conditions suggests that the glycolytic rate is controlled by factors related to energy state. 
BJ2008/2135, Activation of skeletal muscle glycolysis

\section{INTRODUCTION}

Skeletal muscle energy turnover can increase more than 100 fold during high intensity exercise. Thus, the muscle is faced with intricate problems related to fuel homeostasis and metabolic regulation. The precision of adjusting the rate of ATP generating processes to the energy requirements is remarkable and is achieved by both feedforward and feedback control [1]. Carbohydrate $(\mathrm{CHO})$ utilization is of major importance for ATP regeneration during exercise and therefore a precise control of the rate of glycolysis is required. The rate of glycogen utilization is in the order of 3-4 mmol glycosyl units $\mathrm{kg}^{-1} \mathrm{~min}^{-1}$ at $100 \% \mathrm{VO}_{2} \max$, and can increase to $30-50 \mathrm{mmol}$ glycosyl units $\mathrm{kg}^{-1} \mathrm{~min}^{-1}$ during maximal dynamic or static contractions [2]. Despite its key importance in metabolism and despite intensive research the control of glycolysis during exercise is not fully understood.

The conventional view of glycogenolytic/glycolytic control in muscle is that glycogen phosphorylase (GP) and phosphofructokinase (PFK) are the key rate limiting steps. GP is activated by increases in the concentration of allosteric modulators (AMP, inosine monophosphate (IMP)) and substrate (inorganic phosphate $\left(\mathrm{P}_{\mathrm{i}}\right)$ ) and by phosphorylation of the less active form $(\mathrm{GPb})$ into the more active form $(\mathrm{GPa})$. Phosphorylation of $\mathrm{GPb}$ is catalyzed by phosphorylase kinase, which in turn is activated by the cyclic AMP cascade and/or $\mathrm{Ca}^{2+}$. PFK activity is regulated by the concentrations of adenine nucleotides, $\mathrm{P}_{\mathrm{i}}$, citrate, and fructose bisphosphates. Furthermore, $\mathrm{Ca}^{2+}$ and calmodulin have been shown to increase the activity of PFK and to act synergistically with increased levels of AMP and ADP [3]. However the allosteric effect of $\mathrm{Ca}^{2+}$ and calmodulin were measured in vitro with diluted enzyme and the role of $\mathrm{Ca}^{2+}$ in activating PFK needs to be established at physiological enzyme concentrations or alternatively confirmed in whole muscle.

Glycolytic flux, which is intimately related to glycogenolytic flux, increases several-fold during muscle contraction in close relation to the frequency of muscle activation but is immediately shut down when the contraction terminates even during anaerobic conditions [46]. This suggests that the control of glycolysis is exerted by some factor(s) intimately related to the contraction process. The control of glycolysis in contracting muscle has been studied extensively and two main theories have emerged. One theory is that the rate of glycolysis is under feedback control by the energy demand through increased concentrations of the products of ATP hydrolysis (ADP, AMP and $\mathrm{P}_{\mathrm{i}}$ ). Another possibility is that glycolysis is under feedforward control by cytosolic $\mathrm{Ca}^{2+}$, which changes rapidly in concert with contractile activity $[4,7,8]$. The relative importance of these two factors $\left(\mathrm{Ca}^{2+}\right.$ or energy status) in the regulation of glycolysis has been disputed. Conley et al. [7, 8] used ${ }^{31} \mathrm{P}$ magnetic resonance spectroscopy (MRS) to measure the kinetics of PCr, $\mathrm{P}_{\mathrm{i}}$, ATP, sugar phosphates, and $\mathrm{pH}$ in contracting human muscle. Glycolytic rate, calculated from measured parameters, was similar during ischemic and non-ischemic conditions and thus independent of metabolic feedback by $\mathrm{P}_{\mathrm{i}}, \mathrm{ADP}$ and AMP. The hypothesis that glycolysis is controlled by products of ATP hydrolysis was therefore questioned [7]. The dependence of glycolytic rate on muscle stimulation frequency [8] and independence on feedback control mechanism is consistent with the view that glycolysis is controlled solely by $\mathrm{Ca}^{2+}$ and not by the cellular energy status. However, there are limitations and pitfalls to estimate glycolytic rate with the MRS method. It has been pointed out that the MRS method can result in incorrect calculation of glycolytic rate due to overestimation of changes in muscle $\mathrm{pH}$ in a mixed fiber muscle and an unjustified assumption that lactate accumulation has a lag phase during the initial period of contraction [9]. Therefore, the role of $\mathrm{Ca}^{2+}$ in the control of the glycolytic rate needs to be reinvestigated with alternative experimental techniques.

Several textbooks convey the message that increases in $\mathrm{Ca}^{2+}$ is the major factor in the control of glycogenolysis during exercise [10-13], whereas others conclude that metabolic feedback 
by energy status is an important part of the control [14]. Control of glycolysis in contracting muscle is a fundamental issue of great importance for our understanding of muscle energetics. It is therefore important to clarify this point by further experimental work.

A possible experimental approach to investigate this issue would be to dissociate the normal $\mathrm{Ca}^{2+}$ transients in a contracting muscle from energy turnover. A potential tool to maintain normal $\mathrm{Ca}^{2+}$ transients during excitation while decreasing ATP-turnover, is the cross-bridge cycle blocker, $N$-benzyl-p-toluene sulphonamide (BTS). More specifically BTS suppresses force production by inhibiting the release of $\mathrm{P}_{\mathrm{i}}$ together with a decrease in the apparent affinity for $\mathrm{S}^{*} \mathrm{ADP} * \mathrm{Pi}$ and $\mathrm{S} 1 * \mathrm{ADP}$ for actin and BTS appears to act specifically on the myosin heavy chain type II isoform $[15,16]$. Furthermore, BTS does not alter the $\mathrm{Ca}^{2+}$ transients of electrically stimulated single fibers from rabbit [15] or mouse [17, 18], it does not impair normal muscle excitability [19], and it does not affect the sarcoplasmic reticulum (SR) $\mathrm{Ca}^{2+}$ pump ATP utilization [20]. The ability to inhibit cross-bridge cycling with BTS, thereby decreasing ATP-turnover in the muscle cell, without altering any of the upstream processes in the E-C coupling such as SR $\mathrm{Ca}^{2+}$ transients, makes BTS an excellent tool for the study of the role of $\mathrm{Ca}^{2+}$ and/or metabolites in the activation of skeletal muscle glycogenolysis.

In previous studies it was reported that there is a strong correlation between muscle lactate accumulation and PCr levels during both static and dynamic contractions [21]. The $\mathrm{PCr} /$ lactate ratio links glycolytic flux and the creatine kinase reaction and is therefore an ideal tool to distinguish abnormalities in energy metabolism. Contracting muscle incubated with BTS has a low energy turnover, whereas $\mathrm{Ca}^{2+}$ transients are maintained similar as in muscles not treated with BTS. If the hypothesis that $\mathrm{Ca}^{2+}$ is an important trigger of glycolysis is correct, one would expect that the relative ATP provision by glycolysis would increase in BTS treated muscles. Another approach is to inhibit aerobic ATP formation in quiescent muscle by cyanide and thus to increase the rate of anaerobic ATP formation (PCr utilization and glycolysis) without increases in $\mathrm{Ca}^{2+}$. If the hypothesis that $\mathrm{Ca}^{2+}$ is an important trigger of glycolysis is correct, one would, due to the absence of $\mathrm{Ca}^{2+}$ transients, expect that the relation would change towards a lower lactate and a higher PCr utilization. Conversely, if glycolysis is controlled by energy status one would expect that the relation between $\mathrm{PCr}$ and lactate would be similar as in stimulated control muscles both in muscles treated with BTS and during prolonged cyanide treatment.

It is generally accepted that actomyosin ATPase accounts for the majority of the ATP consumed during muscle contractions at maximal or near maximal force, i.e. 50-80\% of total energy consumption [18, 22-30]. BTS selectively inhibits the cross-bridge cycling, while muscle ion pumping remains unchanged, thereby enabling precise estimation of the relative energy utilization by the contractile apparatus. Using BTS cross-bridge ATP requirement during isometric contractions has recently been reported to be $20-30 \%$ of overall ATP consumption [31], which advocate for further estimates of the relative cross-bridge ATP utilization.

The aim of the present study was, therefore, to test the hypothesis that the glycolytic- and glycogenolytic rates are controlled by cellular energy status and not by a direct effect of $\mathrm{Ca}^{2+}$ on the regulating enzymes. We have specifically investigated the effect of modified energy turnover, while maintaining unchanged $\mathrm{Ca}^{2+}$ transients by using the cross-bridge cycling blocker BTS and the effect of blunted $\mathrm{Ca}^{2+}$ transients by incubating muscles with cyanide for a prolonged period. A second purpose of the study was to determine the relative ATPturnover by the cross-bridge cycling during intermittent static contractions. Our findings demonstrate that the glycogenolytic rate is controlled by factors related to energy state, but not directly by increases in $\mathrm{Ca}^{2+}$ and that cross-bridge cycling accounts for $60 \%$ of skeletal muscle total energy turnover during intermittent static contractions. 


\section{EXPERIMENTAL}

Animals, preparation and incubation of muscles. All handling and use of animals complied with Danish animal welfare regulations. Experiments were performed using 12-week-old Wistar rats, weighing approximately $250 \mathrm{~g}$, which were kept in a thermostated environment at $21{ }^{\circ} \mathrm{C}$ with a $12 \mathrm{~h} / 12 \mathrm{~h}$ light - dark cycle and fed ad libitum. The animals were killed by cervical dislocation, followed by decapitation. Intact extensor digitorum longus (EDL) muscles were prepared and incubated in standard Krebs-Ringer bicarbonate buffer (KR) containing the following (in $\mathrm{mM}$ ): $122.1 \mathrm{NaCl}, 25.1 \mathrm{NaHCO}_{3}, 2.8 \mathrm{KCl}, 1.2 \mathrm{KH}_{2} \mathrm{PO}_{4}, 1.2$ $\mathrm{MgSO}_{4}, 1.3 \mathrm{CaCl}_{2}$ and $5.0 \mathrm{D}$-glucose (pH 7.4). All incubations were performed at $25{ }^{\circ} \mathrm{C}$ under continuous gassing with a mixture of $95 \% \mathrm{O}_{2}$ and $5 \% \mathrm{CO}_{2}$.

Force Measurements. Muscles were mounted for isometric contractions in thermostated chambers containing standard KR buffer and adjusted to optimal length for force production. After a $30 \mathrm{~min}$ rest, muscle contractility was tested once, using a short $0.5 \mathrm{~s}$ train of $60 \mathrm{~Hz}$, $0.2 \mathrm{~ms}, 12 \mathrm{~V}$ supramaximal pulses (initial F). Muscles were then incubated in a standard KR buffer for $90 \mathrm{~min}$, or with $50 \mu \mathrm{M} \mathrm{N}$-benzyl-p-toluene sulphonamide (BTS) for matching time. As BTS was dissolved in dimethyl- $\mathrm{d}_{6}$ sulphoxide (DMSO), an equivalent amount of DMSO $(0.05 \%)$ was added to control muscles. For the final $5 \mathrm{~min}$ of the $90 \mathrm{~min}$ incubation, standard KR buffer was replaced with glucose-free KR buffer containing $2 \mathrm{mM} \mathrm{NaCN}$, which prevented glucose transport into the muscle cell and mitochondrial oxygen utilization, respectively. Muscles then underwent fatiguing stimulation using $0.2 \mathrm{~s}$ trains of $60 \mathrm{~Hz}, 0.2$ $\mathrm{ms}, 12 \mathrm{~V}$ supramaximal pulses every $4 \mathrm{~s}$ until force was reduced to $70 \%$ of initial force response (Con). BTS treated muscles were stimulated for an equal time as Con muscle. Resting values were obtained from the corresponding contralateral muscles (Con rest and BTS rest), which were treated as above, i.e. incubated with or without BTS for 90 min and 2 $\mathrm{mM} \mathrm{NaCN}$ for the last $5 \mathrm{~min}$ plus the corresponding time of the stimulation protocol $(88 \mathrm{~s})$. Furthermore, a series of muscles underwent fatiguing stimulation until force was reduced to $85 \%$ of initial force response $\left(\operatorname{Con}^{1} / 2, n=4\right)$. In order to elucidate the effect of an increased energy turnover on muscle metabolite levels, during resting $\left[\mathrm{Ca}^{2+}\right]$, an additionally series of resting muscles $(\mathrm{n}=12)$ were incubated with $2 \mathrm{mM}$ cyanide for $10 \mathrm{~min}$, at a higher temperature $\left(30^{\circ} \mathrm{C}\right)$.

Force was measured using force displacement transducers and recorded with a chart recorder and digitally on a computer. Results are expressed as a percentage of initial F.

Immediately following fatiguing stimulation, the chamber was lowered, leaving the muscle suspended in air, before the muscles were rapidly detached and frozen in liquid $\mathrm{N}_{2}$ while stirring and stored at $-80{ }^{\circ} \mathrm{C}$ until assessment of metabolites. This entire procedure was completed in less than $5 \mathrm{~s}$. A sample of the buffer $(1 \mathrm{ml}$ from a total of $7 \mathrm{ml})$ was taken for determination of lactate that has been released from the muscle into the solution during the fatiguing stimulation.

Metabolite Measurements. Muscles were frozen and later freeze-dried, dissected free of nonmuscle tissue, powdered and extracted with perchloric acid as previously described [32]. Neutralized extracts were analyzed for lactate (Lac), ATP, ADP, AMP, phosphocreatine $(\mathrm{PCr})$, creatine $(\mathrm{Cr})$, glucose, glucose 1-phosphate (G-1-P), glucose 6-phosphate (G-6-P), fructose 6-phosphate (F-6-P) and pyruvate (Pyr), as previously described [32]. In order to adjust for variability in solid non-muscle constituents and weighing variability, all values are normalized by dividing by the total amount of creatine $(\mathrm{PCr}+\mathrm{Cr})$ and multiplied by the mean of total creatine for the whole material (145.1 mmol/kg dry muscle). In addition the buffer solution was analyzed for lactate the same way as the muscle extract in order to estimate the 
total muscle lactate production. Muscle glycogen was analyzed from a separate portion of the freeze dried muscle according to Lowry and Passonneau [33]. The metabolic changes after stimulation of Con and BTS muscles were calculated from the difference from the nonstimulated contralateral muscles in each animal.

Calculations. Glycolytic intermediates (GI) was calculated as the sum of glucose, G-6-P, G-1$\mathrm{P}$ and F-6-P. Lac was determined from the sum of muscle Lac and Lac released to the buffer. ATP utilization was estimated from substrate phosphorylation as: $-\triangle \mathrm{PCr}-(2 \Delta \mathrm{ATP}-\triangle \mathrm{ADP})$ $+1.5 \Delta \mathrm{Lac}+1.5 \Delta \mathrm{Pyr}$, where $\Delta$ refers to the difference between metabolite concentration in the stimulated muscle and the contralateral resting muscle. Glycolytic flux was calculated by the equation; $(\Delta \mathrm{Lac}+\Delta \mathrm{Pyr}) / 2$, and calculated glycogenolytic flux from the sum of glycolytic flux and accumulated glycolytic intermediates. Muscle $\mathrm{pH}\left(\mathrm{pH}_{\mathrm{m}}\right)$ was determined using the equation: $\mathrm{pH}_{\mathrm{m}}=7.06-0.00532$ (lactate + pyruvate) [34]. Muscle free ADP and free AMP are the metabolically active forms, and have been estimated from the creatine kinase and adenylate kinase equilibrium [35].

The metabolic rates are given per total time of stimulation, $88 \mathrm{~s}$ (Con) and $90 \mathrm{~s}$ (BTS). The force-time integral, calculated as the area below the force tracings, was used as an estimate of the isometric "work".

Chemicals. All chemicals were of analytical grade and unless stated were obtained from Sigma-Aldrich, with BTS obtained from Toronto Research Chemicals, Ontario, Canada.

Statistics. Statistical comparisons were made using either Student's t-test or one-way analysis of variance (ANOVA), where appropriate. Significant differences between means were located using the Bonferroni post hoc test. Statistical significance was accepted at $P<0.05$. All values are given as mean $\pm \mathrm{SE}$.

\section{RESULTS}

Force production and force-time integrals during fatiguing isometric stimulation. Summarized data of force production during fatiguing stimulation are shown in Figure 1. Muscles were stimulated intermittently at $60 \mathrm{~Hz}$ until force was reduced to $70 \%$ (Con) of initial force response, which corresponded to $88.4 \pm 8.6 \mathrm{~s}$ (Fig. 1). Initial force averaged 0.81 $\pm 0.05 \mathrm{~N}$ for Con, which corresponds to $83 \%$ of maximum tetanic force $(100 \mathrm{~Hz})$. The initial force, in stimulated BTS muscle, was $17 \pm 2.1 \%$ of that in Con and did not significantly change during the 90s stimulation (Fig. 1). The isometric "work" (force-time integral) in BTS muscles was only $38 \%$ of that in Con muscles $(1.25 \pm 0.00 \mathrm{Ns}$ and $3.30 \pm 0.24 \mathrm{Ns}$, respectively). Thus, BTS muscles had a much lower force production and isometric "work" than Con. There were no difference in force-time integral between Con $1 \frac{1}{2}$ muscles, stimulated until force was reduced to $85 \%$ of initial force response $(41.6 \pm 3.4 \mathrm{~s})$, and BTS treated muscles.

\section{Figure 1 and table 1 near here}

Muscle metabolites. Muscle metabolites measured in stimulated muscles and in the respective contralateral non-stimulated muscles incubated for the same time and under the same conditions are presented in Table 1 and 2. There was no difference between conditions in metabolite contents of non-stimulated muscles. Thus, in agreement with previous reports BTS did not alter resting metabolite levels [36]. Muscle contents of ATP, PCr and lactate are in the same order as those previously reported for rat muscle [36] as well as for similar sized large rat and muscles immediately excised and frozen [37]. This demonstrates that pre-incubation of muscles in oxygenated Krebs-Ringer solution for $90 \mathrm{~min}$ with addition of cyanide during 
the final $5 \mathrm{~min}$ of incubation had minor influence on muscle metabolites. However, when non-stimulated muscles were incubated with cyanide at $30{ }^{\circ} \mathrm{C}$ for $10 \mathrm{~min}(\mathrm{n}=12)$, muscle lactate increased 7-fold (35.4 $\left.\pm 1.7 \mathrm{mmol} \mathrm{kg}^{-1} \mathrm{dw}\right)$ and PCr decreased to $39 \%$ of initial level $\left(40.0 \pm 2.8 \mathrm{mmol} \mathrm{kg}^{-1} \mathrm{dw}\right)$. In Con $1 \frac{1}{2}$ muscles ATP levels did not change during the stimulation in either of the protocols, while ADP was significantly increased and the ATP/ADP ratio was significantly decreased following the stimulation in all protocols. However, a large fraction of ADP and AMP is considered to be bound to proteins or otherwise sequestered in the cell, thus the muscle concentration of the metabolic active forms were estimated. Both $\left[\mathrm{ADP}_{\text {free }}\right]$ and $\left[\mathrm{AMP}_{\text {free }}\right]$ were significantly increased after contractions, with a 2 and 4 fold higher concentration of $\left[\mathrm{ADP}_{\text {free }}\right]$ and $\left[\mathrm{AMP}_{\text {free }}\right]$, respectively in Con compared to BTS muscles (Table 1). PCr decreased by $73 \%$ in Con muscles, with a significantly less severe decrease in BTS $(48 \%)$ and $\operatorname{Con}^{1} \frac{1}{2}(51 \%)$ muscles. The decrease in $\mathrm{PCr}$ was paralleled by a similar increase in Cr. The relative ATP provision from PCr and glycolysis to the total ATP utilization was not significant different between protocols (Table 3 ). Both Con and BTS muscles showed an increase in glycolytic intermediates (GI = glucose+G-6-P+G-1-P+F-6-P) following stimulation, with most pronounced being the 5-6 fold increases in G-6-P and F-6-P. Further, there was a significant higher concentration of both total GI and G-6-P following stimulation in Con than in BTS. Lactate and pyruvate levels increased significantly during both conditions, with the increase being about 1.5 -fold higher in Con than in BTS muscles. In line with the increase in Lac, there was a larger decrease in muscle glycogen levels in Con muscles $(22 \%)$ than in BTS $(12 \%)$ muscles, and no difference in resting levels. Using the values for lactate and pyruvate, $\mathrm{pH}_{\mathrm{m}}$ was estimated following stimulation (Table 2). The $\mathrm{pH}_{\mathrm{m}}$ decreased from resting value following both treatments, but reached a lower level in Con muscles than in BTS treated muscles.

\section{Table 2 and 3 near here}

ATP turnover. Using the metabolite values it was possible to calculate the ATP utilization, ATP turnover and the rate of ATP utilization during contraction (Table 3). ATP utilization in BTS was $58 \%$ of that in Con and the turnover of ATP was significantly higher (77\%) in Con than in BTS muscles despite similar duration of stimulation. In line with this, the ATPturnover per stimulation time was significantly lower in BTS treated muscles compared to Con muscles (Table 3). When the ATP utilization was related to the amount of isometric "work", BTS muscles had a significantly higher ATP utilization than Con muscles, due to the inhibition of cross-bridge cycling, while maintaining normal SR and sarcolemma/t-tubule ionpumping (Table 3).

\section{Figure 2 near here}

Glycolytic flux and glycolytic rates. There was a significantly lower glycolytic flux in BTS $\left(12.5 \pm 1.1 \mathrm{mmol}\right.$ glycosyl units $\left.\mathrm{kg}^{-1} \mathrm{dw}\right)$ muscles, averaging $54 \%$ of that in Con muscles $\left(23.6 \pm 0.5 \mathrm{mmol}\right.$ glycosyl units $\left.\mathrm{kg}^{-1} \mathrm{dw}\right)$. The effect of inhibiting cross-bridge cycling, while maintaining normal $\mathrm{Ca}^{2+}$ transients, on the glycolytic rate is presented in Figure 2A. In BTS treated muscle, the glycolytic rate was about half of that in Con muscles.

Glycogenolytic flux and glycogenolytic rates. Glycogenolytic flux was estimated both from direct measures of the decrease in muscle glycogen content following stimulation (observed glycogenolysis), as well as from calculations based on the increase in lactate, pyruvate and GI (see Calculations). There was a good agreement between observed- and calculated glycogenolytic flux (Table 2). Glycogenolytic flux was almost 2 fold higher in Con than BTS treated muscles. Despite differences in glycogenolytic flux, there were no differences between 
groups, in relation to the relative contribution of lactate, pyruvate and GI in the calculated glycogenolytic flux, accounting on average for $88 \%, 1 \%$ and $11 \%$ of the glycosyl units, respectively. The glycogenolytic rate was on average 2-fold lower in BTS treated muscles compared to Con (Fig. 2B).

\section{Figure 3 near here}

$P C r$ vs. lactate levels. In a previous study it was reported that there was a strong logarithmic correlation between human muscle lactate accumulation and $\mathrm{PCr}$ levels [21]. We wanted to test if this correlation also would fit with BTS treated muscles, having an approximately 2fold lower energy turnover while having same $\mathrm{Ca}^{2+}$ transients as Con muscles. The curvilinear relationship between $\mathrm{PCr}$ and lactate derived from Con rest, Con stimulated and $\mathrm{Con} 1 / 2$ muscles, can be described by the two phase exponential decay equation: $\mathrm{PCr}=59.6 \mathrm{e}^{-0.035 \mathrm{Lac}}+$ $54.8 \mathrm{e}^{-0.035 \mathrm{Lac}}$ (Figure 3). Even in our data, using rat muscle, there is a strong relation between PCr and lactate $\left(r^{2}=0.95\right)$, with the BTS treated muscles fitting well with the correlation. In line with this, the calculated contribution of $\mathrm{PCr}$ to the total energy turnover was not significantly different between conditions (Table 3). This demonstrates that treatment with BTS does not affect the relation between $\mathrm{PCr}$ and lactate. If the hypothesis that $\mathrm{Ca}^{2+}$ is an important trigger of glycolysis is correct, one would expect that the relative ATP provision by glycolysis would increase in BTS treated muscles. PCr and lactate levels fitted well with the correlation when the aerobic ATP formation was inhibited by cyanide in quiescent muscle, i.e. increased rate of anaerobic ATP formation ( $\mathrm{PCr}$ utilization and glycolysis) without increasing intracellular $\mathrm{Ca}^{2+}$. This observation supports the idea that glycolysis is controlled by energy status and argues against the hypothesis that $\mathrm{Ca}^{2+}$ is an important trigger of glycolysis.

\section{Figure 4 near here}

Relative ATP utilization by the cross-bridge cycling. A second purpose of the study was to determine the relative ATP utilization by cross-bridge cycling during intermittent static contractions. The relationship between isometric "work" and ATP utilization in Con and BTS treated muscles is shown in Figure 4. Extrapolating the line defining the relationship to zero isometric "work", gives an estimate of the ATP utilization by processes other than crossbridge cycling Energy utilization by Con muscles averaged 146 mmol ATP kg-1 dw (Table 3) and the intercept, i.e. non-contractile energy utilization, was $59 \mathrm{mmol} \mathrm{ATP} \mathrm{kg}^{-1} \mathrm{dw}$, with a $95 \%$ confidence interval of 43 - 74. Thus, under our conditions of intermittent static contractions, non-contractile energy utilization on average accounted for $40 \%(29-51 \%)$ and the cross-bridge cycling corresponds to $60 \%$ (49-71\%) of the total energy utilization.

\section{DISCUSSION}

The major observation of this study is that the rates of glycogenolysis and glycolysis in contracting muscle are reduced when energy turnover is reduced, despite maintenance of the same normal $\mathrm{Ca}^{2+}$ transients as during contractions. The relative glycolytic rate during prolonged cyanide treatment was also independent of $\mathrm{Ca}^{2+}$ transients. This demonstrates that glycolytic flux is controlled by factors related to energy state, but not by $\mathrm{Ca}^{2+}$ directly. A second observation is that, using the cross-bridge cycle inhibitor BTS, estimates of the ATPturnover demonstrate that the cross-bridge cycling accounts for about $60 \%$ of the total energy turnover by the skeletal muscle during intermittent static contractions. 
Regulation of glycolytic and glycogenolytic rates. Our findings are consistent with previous studies showing a close relation between the rate of glycolysis and energy turnover [6]. By using BTS we were able to construct an experimental model where changes in energy turnover were disconnected from parallel changes in $\mathrm{Ca}^{2+}$ transients i.e. reduced energy turnover but maintained $\mathrm{Ca}^{2+}$ transients. Several lines of observation from the present study demonstrate that the glycolytic rate is controlled by factors other than by a direct effect of $\mathrm{Ca}^{2+}$ on the flux controlling enzymes. Firstly, the glycolytic rate in the BTS treated muscles was only half of that in the Con muscles (Table 3). Since muscles treated with BTS maintain normal $\mathrm{Ca}^{2+}$ transients but have reduced ATP turnover, this strongly indicates that the glycolytic rate is controlled by energy state and not by a direct effect of $\mathrm{Ca}^{2+}$. Secondly, the relationship between PCr and lactate was independent of BTS (Fig. 3) and the relative contribution of $\mathrm{PCr}$ and glycolysis to the energy turnover was not different between conditions (Table 3). If $\mathrm{Ca}^{2+}$ is the key factor in the control of glycolytic rate, one would expect that lactate concentration in BTS muscles would be higher than that observed, resulting in a higher relative glycolytic ATP production vs. Con and a right-ward shift of the relation shown in Figure 3. Thirdly, using prolonged cyanide treatment of quiescent muscle, intracellular $\mathrm{Ca}^{2+}$ levels remain low while energy supply is covered by anaerobic ATP formation. With this experimental approach the relation between $\mathrm{PCr}$ and lactate was not changed. If $\mathrm{Ca}^{2+}$ is an important trigger of glycolysis one would, due to the absence of $\mathrm{Ca}^{2+}$ transients in resting muscle, expect that the relation would change towards a lower lactate and a higher PCr utilization. On the basis of our results we conclude that the glycolytic rate is controlled by factors related to energy state but not by $\mathrm{Ca}^{2+}$ directly.

Furthermore, the theoretical base for $\mathrm{Ca}^{2+}$ being the trigger of increased glycolysis is weak. Although the activation of phosphorylase $\mathrm{b}$ kinase by $\mathrm{Ca}^{2+}$ and the contraction-induced transformation of $\mathrm{GPb}$ into the more active GPa are well established, there is no clear cut relation between the fraction of GP in the form of GPa and glycogenolytic rate. Firstly GPa levels are already high in resting muscle (about $10 \%$ of total GP) despite a low rate of glycogenolysis [38]. Secondly, GPa increases transiently at the onset of contraction, but is reverted back to the basal level during sustained contraction despite high rates of glycogenolysis [38]. Thirdly, when GP is almost totally converted to GPa by epinephrine administration, the glycolytic rate only increases to a minor extent, and is maintained below that during intensive exercise [39]. It can be concluded that if $\mathrm{Ca}^{2+}$ is the main trigger of glycogenolysis and glycolysis this must occur through a mechanism different from conversion of GPb to GPa. In line with this contention Crowther et al. [40] showed that hexose phosphate levels remained high when exercise and glycolytic flux ceased and they concluded that glycolysis was controlled independently of glycogenolysis. As an alternative to activation of GP by $\mathrm{Ca}^{2+}$ they suggested that glycolytic rate was directly influenced by $\mathrm{Ca}^{2+}$ through $\mathrm{Ca}^{2+}$ initiated phosphorylation of glycolytic enzymes and/or via $\mathrm{Ca}^{2+}$-mediated binding of these enzymes to the cytoskeleton. The findings in this study give no support for such a mechanism but on the contrary demonstrate that glycolytic flux is not controlled by $\mathrm{Ca}^{2+}$ directly. However, the possibility that $\mathrm{Ca}^{2+}$ has a permissive role and that there is a "dual-control" model [41] to achieve high rates of glycolysis can not be excluded.

An important assumption for the above conclusion is that skeletal muscle intracellular $\mathrm{Ca}^{2+}$ transients $\left(\left[\mathrm{Ca}^{2+}\right]_{\mathrm{i}}\right)$, are the same during conditions, i.e. not affected by BTS and/or contractions. BTS has been identified as a highly specific inhibitor of myosin II ATPase that does not interfere with $\left[\mathrm{Ca}^{2+}\right]_{i}$, which has consistently been shown by direct measures of $\left[\mathrm{Ca}^{2+}\right]_{\mathrm{i}}$ in rabbit psoas muscle [15], mouse toe muscle [17, 31], and as in the present study, rat fast twitch muscle [42]. Further there is no effect of BTS on muscle excitability [19, 36] or SR $\mathrm{Ca}^{2+}$ pump ATP utilization [20]. Although tetanic $\left[\mathrm{Ca}^{2+}\right]_{\mathrm{i}}$ is relatively stable in isolated fibres, stimulated for several minutes using a similar protocol as in present study $(350 \mathrm{~ms}$ 
every $2.5-4 \mathrm{~s}$, [43]), it is conceivable that $\left[\mathrm{Ca}^{2+}\right]_{\mathrm{i}}$ is decreased at fatigue during the $90 \mathrm{~s}$ stimulation in Con. Importantly, this would strengthen our proposition that the glycolytic rate is controlled by other factors than by a direct effect of $\mathrm{Ca}^{2+}$ on the flux controlling enzymes. Thus, BTS muscles not developing fatigue, i.e. no decrease in $\left[\mathrm{Ca}^{2+}\right]_{\mathrm{i}}$, have a lower glycolytic rate compared to Con muscles with a conceivably decreased $\left[\mathrm{Ca}^{2+}\right]_{i}$, while still having a substantially higher glycolytic rate.

The present study demonstrates that the rates of glycolysis and glycogenolysis are more closely related to energy state than to intracellular $\mathrm{Ca}^{2+}$ transients. An elevated rate of ATPturnover leads to increased muscle concentration of ADP, and due to the presence of the adenylate kinase reaction, to even larger increases in AMP. Calculated $\mathrm{ADP}_{\text {free }}$ increased about 7 times after stimulation in Con, which was 2 fold higher than that in stimulated BTS (Table 1). AMP is a more potent activator of GP and PFK than ADP [2] and increases the affinity of GP for $\mathrm{P}_{\mathrm{i}}$ and PFK for F-6-P. Calculated $\mathrm{AMP}_{\text {free }}$ increased about 50 times after stimulation in Con, which was about 4 times higher than that in BTS (Table 1). The concentration of AMP after stimulation was $3.4 \mu \mathrm{M}$ and $0.8 \mu \mathrm{M}$ in Con and BTS, respectively and is within the range where GP is activated [6]. An increase in AMP is therefore an attractive candidate for linking ATP-turnover to increased rates of glycolysis.

The glycolytic flux is immediately shut off when the contraction terminates. This is the case even during ischemic conditions when the metabolic state is clamped with elevated levels of $\mathrm{ADP}_{\text {free }}$ and $\mathrm{AMP}_{\text {free }}[4,21,40,41,44]$. Studies using magnetic resonance spectroscopy (MRS), which has a high temporal resolution, have confirmed the finding of an immediate arrest of glycolytic rate during ischemic conditions [5]. The low rate of glycolysis in ischemic quiescent muscle, despite elevated ADP and AMP levels has been taken as an evidence that glycolysis is not solely controlled by elevated metabolites [4, 40, 41]. However, the concentration of $\mathrm{ADP}_{\text {free }}$ and $\mathrm{AMP}_{\text {free }}$ are calculated under the presumption that the creatine kinase and adenylate kinase reaction are at equilibrium without cellular concentration gradients. This is likely to be an oversimplified model and it was suggested that rapid local changes occur in the concentration of ADP and AMP in a contracting muscle at the ATPutilizing sites and that these are the triggers of glycogenolysis and glycolysis [45]. The hypothesis of transient changes in phosphate metabolites is supported by theoretical modeling [46] and measurement in beating heart with high-resolution MRS [47]. Supporting evidence also comes from the observation that deamination of AMP to inosine monophosphate and ammonia is a process that occurs in a fatigued muscle during contraction but not during the subsequent ischemic recovery [37]. AMP deaminase is stimulated by increases in AMP and the close link between AMP deamination and contraction therefore gives indirect evidence of transient increases in AMP in contracting muscle.

Cross-bridge ATP utilization. The present data shows that the muscle cross-bridge cycling accounts for $60 \%$ (49-71\%) of skeletal muscle total energy turnover during intermittent static contractions under our conditions. This is in line with the general acceptance that actomyosin ATPase accounts for $50-80 \%$ of the ATP consumed during muscle contractions of maximal or near maximal force [18, 22-30]. In the present study we have used BTS, which strongly inhibits cross-bridge cycling without affecting $\mathrm{Ca}^{2+}$ handling $[15,17,18]$. Using BTS, Walsh et al. [18] determined the relative metabolic cost of cross-bridge cycling by estimating the fall in intracellular $\mathrm{PO}_{2}$ in contracting isolated fibers from Xenopus laevis muscle. During intermittent isometric contractions (250 ms every $2-6 \mathrm{~s}$ for $100-200 \mathrm{~s})$ at $20^{\circ} \mathrm{C}$ the relative ATP cost used in cross-bridge cycling was 58\% of overall ATP consumption [18]. Recently, Barclay et al. [30] estimated cross-bridge cycling accounts for slightly less than two-thirds of overall ATP consumption, with no difference in estimates using the reduced filament overlap or BTS. These estimates are very much in line with the present data of $60 \%$ using a more direct approach to determine metabolic cost at similar conditions in mammalian muscle. All 
the above studies, including the present study, have estimated the relative energy turnover by the cross-bridge cycling, by comparing the energy utilization with and without actomyosin ATP turnover (i.e. stretch or BTS). This assumes that cross-bridge cycling efficiency is unaltered during the contractile period. However, muscle fibers increase efficiency with contraction time, most pronounced in fast twitch muscle [48], which is thought to be a result of decreased actomyosin turnover. Thus, the estimated relative ATP consumption by the cross-bridge cycling is an average for the contractile period and as a consequence underestimates ATP consumption for shorter stimulation periods and overestimates for longer stimulation periods.

Recently, Zhang et al. [31] reported that cross-bridge cycling accounts for only $18-25 \%$ of the consumed ATP during repeated tetani for $100 \mathrm{~s}$. The difference in the reported relative myosin ATPase energy utilization may in part be explained by the methods used to estimate the total ATP turnover. Both the present study and Zhang et al. [31] have used cyanide to inhibit oxidative phosphorylation enabling the estimation of ATP utilization by using conventional biochemical methods. There are, however, some limitations and pitfalls with the technique. First, inhibiting the mitochondrial oxidative phosphorylation at $30{ }^{\circ} \mathrm{C}$ may, in contrast to that at $25{ }^{\circ} \mathrm{C}$ (used in the present study) lead to perturbation of the resting muscle metabolite levels i.e. increased lactate and reduced PCr. This may lead to overestimation of total ATP utilization in both Con and BTS and thus reduced relative ATP utilization by the cross-bridge cycling. However, with this in mind the differences between studies in temperature and relative force during contraction, i.e. $25^{\circ} \mathrm{C}$ and $83 \%$ of $\mathrm{F}_{\max }$ (present study) vs. $30{ }^{\circ} \mathrm{C}$ and $35 \% \mathrm{~F}_{\max }$ may, as discussed by Zhang et al. (2006), be an important part of the explanation for the observed differences in relative cross-bridge ATP utilization.

In conclusion, this study demonstrates that reducing energy turnover, during contractions in fast-twitch muscles, while keeping normal $\mathrm{Ca}^{2+}$ transients, results in a proportional decreases in the glycogenolytic and glycolytic rate. This clearly reveals that the rates of glycogenolysis and glycolysis are controlled by factors related to energy turnover but not to $\mathrm{Ca}^{2+}$ directly. Furthermore, estimates of the ATP-turnover with and without inhibiting the cross-bridge cycle, reveal that the cross-bridge cycling accounts for $60 \%$ of the total energy turnover by the skeletal muscle during intermittent static contractions.

\section{ACKNOWLEDGEMENTS}

This study was supported by grants from The Lundbeck Foundation. We thank Professor Torben Clausen and Associate Professor Ole Baekgaard Nielsen for the use of their laboratory for the muscle stimulation experiments, and Marianne Stürup Johansen and Chris Christensen for skilled technical assistance. WA Macdonald's current address is School of Biomedical, Biomolecular and Chemical Sciences, The University of Western Australia, Crawley, Australia.

\section{REFERENCES}

1. Hochachka, P. W. and Matheson, G. O. (1992) Regulating ATP turnover rates over broad dynamic work ranges in skeletal muscles. J. Appl. Physiol. 73, 1697-1703

2. Connett, R. J. and Sahlin, K. (1996) Control of Glycolysis and Glycogen. In Handbook of Physiology. Exercise: regulation and integration of multiple system (Rowel, L. B. and Sheperd, J. T., ed.), pp. 870-911, Am. Physiol. Soc., Bethesda 
3. Mayr, G. W. (1984) Interaction of calmodulin with muscle phosphofructokinase. Interplay with metabolic effectors of the enzyme under physiological conditions. Eur. J. Biochem. 143, 521-529

4. Dawson, M. J., Gadian, D. G. and Wilkie, D. R. (1980) Mechanical relaxation rate and metabolism studied in fatiguing muscle by phosphorus nuclear magnetic resonance. J. Physiol. 299, 465-484

5. Quistorff, B., Johansen, L. and Sahlin, K. (1993) Absence of phosphocreatine resynthesis in human calf muscle during ischaemic recovery. Biochem. J. 291, 681-686

6. Ren, J. M. and Hultman, E. (1990) Regulation of phosphorylase a activity in human skeletal muscle. J. Appl. Physiol. 69, 919-923

7. Conley, K. E., Kushmerick, M. J. and Jubrias, S. A. (1998) Glycolysis is independent of oxygenation state in stimulated human skeletal muscle in vivo. J. Physiol. 511, 935-45

8. Conley, K. E., Blei, M. L., Richards, T. L., Kushmerick, M. J. and Jubrias, S. A. (1997) Activation of glycolysis in human muscle in vivo. Am. J. Physiol. Cell Physiol. 273, C306-C315

9. Sahlin, K. (2005) Determination of muscle $\mathrm{pH}$ and glycolytic flux by magnetic resonance spectroscopy in contracting human skeletal muscle may have systematic errors. Am. J. Physiol. Cell Physiol. 289, C230

10. Brooks, G. A. and Fahey, T. D. (1984) Exercise Physiology: Human bioenergetics and its applications, p. 85, Macmillan Publishing Company, New York.

11. Maughan, R. and Gleeson, M. (2004) The Biochemical basis of Sports Performance, p. 101, Oxford University Press, Oxford.

12. Newsholme, E. A. and Leech, A. (1983) Biochemistry for the Medical Science, p. 327, John Wiley and Sons, Chichester.

13. Voet, D., and Voet, J. G. (1995) Biochemistry, $2^{\text {nd }}$ ed. p. 500, Wiley and Sons, Chichester.

14. Houston, M. E. (2006) Biochemistry primer for exercise science, $3^{\text {rd }}$ ed., pp. 116-119, Human Kinetics, Champaign.

15. Cheung, A., Dantzig, J. A., Hollingworth, S., Baylor, S. M., Goldman, Y. E., Mitchison, T. J. and Straight, A. F. (2002) A small-molecule inhibitor of skeletal muscle myosin II. Nature Cell Biol. 4, 83-88

16. Shaw, M. A., Ostap, E. M. and Goldman, Y. E. (2003) Mechanism of inhibition of skeletal muscle actomyosin by N-benzyl-p-toluenesulfonamide. Biochem. 42, 6128-6135

17. Bruton, J., Pinniger, G. J., Lannergren, J. and Westerblad H. (2006) The effects of the myosin-II inhibitor N-benzyl-p-toluene sulphonamide on fatigue in mouse single intact toe muscle fibres. Acta Physiol. Scand. 186, 59-66,

18. Walsh, B., Howlett, R. A., Stary, C. M., Kindig, C. A. and Hogan, M. C. (2006) Measurement of activation energy and oxidative phosphorylation onset kinetics in isolated muscle fibers in the absence of cross-bridge cycling. Am. J. Physiol. Regul. Integr. Comp. Physiol. 290, R1707-R1713

19. Macdonald, W. A., Pedersen, T. H., Clausen, T. and Nielsen, O. (2005) N-Benzyl-ptoluene sulphonamide allows the recording of trains of intracellular action potentials from nerve-stimulated intact fast-twitch skeletal muscle of the rat. Exp. Physiol. 90, 815825

20. Young, I. S., Harwood, C. L. and Rome, L. C. (2003) Cross-bridge blocker BTS permits direct measurement of SR Ca2+ pump ATP utilization in toadfish swimbladder muscle fibers. Am. J. Physiol. Cell Physiol. 285, C781-C787

21. Harris, R. C., Edwards, R. H., Hultman, E., Nordesjö, L. O., Nylind, B. and Sahlin, K. (1976) The time course of phosphorylcreatine resynthesis during recovery of the quadriceps muscle in man. Pflugers Arch. 367, 137-142 
22. Baker, A. J., Brandes, R., Schendel, T. M., Trocha, S. D., Miller, R. G. and Weiner, M. W. (1994) Energy use by contractile and noncontractile processes in skeletal muscle estimated by 31P-NMR. Am. J. Physiol. Cell Physiol. 266, C825-C831

23. Homsher, E., Mommaerts, W. F., Ricchiuti, N. V. and Wallner, A. (1972) Activation heat, activation metabolism and tension-related heat in frog semitendinosus muscles. J. Physiol. 220, 601-625

24. Horiuti, K., Higuchi, H., Umazume, Y., Konishi, M., Okazaki, O. and Kurihara, S. (1988) Mechanism of action of 2,3-butanedione 2-monoxime on contraction of frog skeletal muscle fibres. J. Muscle Res. Cell. Motil. 9, 156-164

25. Kushmerick, M. J. (1988) Energetics of muscle contraction. In Handbook of Physiology. Skeletal Muscle (Peachey, L. D. ed.) pp. 189-236, Am. Physiol. Soc., Bethesda

26. Rall, J. A. and Schottelius, B. A. (1973) Energetics of contraction in phasic and tonic skeletal muscles of the chicken. J. Gen. Physiol. 62, 303-323

27. Rall, J. A. (1982) Energetics of $\mathrm{Ca}^{2+}$ cycling during skeletal muscle contraction. Fed. Proc. 41, 155-160

22. Smith, I. C. (1972) Energetics of activation in frog and toad muscle. J. Physiol. 220, 583-599

29. Homsher, E. and Kean, C. J. (1978) Skeletal muscle energetics and metabolism. Annu. Rev. Physiol. 40, 93-131

30. Barclay C.J., Lichtwark G.A. and Curtin N.A. (2008) The energetic cost of activation in mouse fast-twitch muscle is the same whether measured using reduced filament overlap or N-benzyl-p-toluenesulphonamide. Acta Physiol. 193, 381-391

31. Zhang, S. J., Andersson, D. C., Sandstrom, M. E., Westerblad, H. and Katz, A. (2006) Cross bridges account for only $20 \%$ of total ATP consumption during submaximal isometric contraction in mouse fast-twitch skeletal muscle. Am. J. Physiol. Cell Physiol. 291, C147-C154

32. Harris, R. C., Hultman, E. and Nordesjö, L. O. (1974) Glycolytic intermediates in human muscle after isometric contraction. Scand. J. Clin. Lab. Invest. 33, 109-120

33. Lowry, O. H. and Passonneau, J.V. (1972) A Flexible System on Enzymatic Analysis. New York: Academic Press

34. Sahlin, K., Harris, R. C., Nylind, B. and Hultman, E. (1976) Lactate content and pH in muscle obtained after dynamic exercise. Pflugers Arch. 367, 143-149

35. Veech, R. L., Lawson, J. W., Cornell, N. W. and Krebs, H. A. (1979) Cytosolic phosphorylation potential. J. Biol. Chem. 254, 6538-654745.

36. Macdonald, W. A., Ørtenblad, N. and Nielsen, O.B. (2007) Energy conservation attenuates the loss of skeletal muscle excitability during intense contractions. Am. J. Physiol. Endocrinol. Metab. 292, E771-E778

37. Sahlin, K., Gorski, J. and Edstrom, L. (1990) Influence of ATP turnover and metabolite changes on IMP formation and glycolysis in rat skeletal muscle. Am. J. Physiol. 259, C409-C412

38. Chasiotis, D., Sahlin, K. and Hultman, E. (1982) Regulation of glycogenolysis in human muscle at rest and during exercise. J. Appl. Physiol. 53, 708-715

39. Chasiotis, D., Sahlin, K. and Hultman, E. (1983) Regulation of glycogenolysis in human muscle in response to epinephrine infusion. J. Appl. Physiol. 54, 45-50

40. Crowther, G. J., Kemper, W. F., Carey, M. F. and Conley, K. E. (2002) Control of glycolysis in contracting skeletal muscle I. Turning it on. Am. J. Physiol. Endocrinol. Metab. 282, E74-E79

41. Crowther, G. J., Carey, M. F., Kemper, W. F. and Conley, K. E. (2002) Control of glycolysis in contracting skeletal muscle. II. Turning it off. Am. J. Physiol. Endocrinol. Metab. 282, E67-E73 
42. Pinniger, G. J., Bruton, J. D., Westerblad, H. and Ranatunga, K. W. (2005) Effects of a myosin-II inhibitor (N-benzyl-p-toluene sulphonamide, BTS) on contractile characteristics of intact fast-twitch mammalian muscle fibres. J. Muscle Res. Cell. Motil. 26, 135-41

43. Westerblad, H. and Allen, D. G. (1991) Changes of myoplasmic calcium concentration during fatigue in single mouse muscle fibers. J. Gen. Physiol. 98, 615-35

44. Harris, R. C., Hultman, E. and Sahlin, K. (1981) Glycogen, glycolytic intermediates and high-energy phosphates determined in biopsy samples of musculus quadriceps femoris of man at rest. Methods and variance of values. Pflugers Arch. 389, 277-282

45. Katz, A. and Sahlin, K. (1990) Role of oxygen in regulation of glycolysis and lactate production in human skeletal muscle. Exerc. Sport Sci. Rev. 18, 1-28

46. Saks, V., Aliev, M., Guzun, R., Beraud, N., Monge, C., Anmannn, T., Kuznetsov, A. V. and Seppet, E. (2006) Biophysics of the organized metabolic networks in muscle and brain cells. Recent Res. Devel. Biophys. 5, 269-318

47. Chung, Y., Sharman, R., Carlsen, R., Unger, S. W., Larson, D. and Jue, T. (1998) Metabolic fluctuation during a muscle contraction cycle. Am. J. Physiol. Cell Physiol. 274, C846-C852

48. Crow, M. T. and Kushmerick, M. J. (1982) Phosphorylation of myosin light chains in mouse fast-twitch muscle associated with reduced actomyosin turnover rate. Science 217, 835-7 


\section{TABLES}

\section{Table 1}

Content of ATP, ADP, AMP, PCr and $\mathrm{Cr}$ in stimulated and non-stimulated muscles. Values are means $\pm \mathrm{SE}$ and are given as $\mathrm{mmol} \mathrm{kg}{ }^{-1}$ dry weight, except $\mathrm{ADP}_{\text {free }}$ and $\mathrm{AMP}_{\text {free }}$ which are $\mu$ mol $\mathrm{kg}^{-1}$ dry weight. $\mathrm{n}=8$ for all conditions. $\mathrm{ADP}_{\text {free }}$ and $\mathrm{ADP}_{\text {free }}$ are calculated concentrations of free ADP and AMP, respectively. "Significant different from the corresponding resting value. ${ }^{\dagger}$ Significantly different from Con.

\begin{tabular}{lcccc}
\hline & $\begin{array}{c}\text { Con } \\
\text { non-stimulated }\end{array}$ & $\begin{array}{c}\text { Con } \\
\text { stimulated }\end{array}$ & $\begin{array}{c}\text { BTS } \\
\text { non-stimulated }\end{array}$ & $\begin{array}{c}\text { BTS } \\
\text { stimulated }\end{array}$ \\
\cline { 2 - 5 } ATP & $29.6 \pm 0.2$ & $29.4 \pm 0.4$ & $28.6 \pm 0.4$ & $28.4 \pm 0.4$ \\
ADP & $3.3 \pm 0.1$ & $4.0 \pm 0.1 *$ & $3.3 \pm 0.1$ & $4.0 \pm 0.1^{*}$ \\
AMP & $0.1 \pm 0.02$ & $0.1 \pm 0.01$ & $0.1 \pm 0.01$ & $0.2 \pm 0.03$ \\
TAN & $33.0 \pm 0.2$ & $33.6 \pm 0.4$ & $32.0 \pm 0.4$ & $32.5 \pm 0.4$ \\
ADP $_{\text {free }}$ & $79.8 \pm 6.2$ & $554.4 \pm 24.2^{*}$ & $85.5 \pm 2.8$ & $272.5 \pm 12.1^{* \dagger}$ \\
$\mathrm{AMP}_{\text {free }}$ & $0.2 \pm 0.04$ & $10.1 \pm 0.9^{*}$ & $0.3 \pm 0.02$ & $2.5 \pm 0.2^{* \dagger}$ \\
$\mathrm{PCr}$ & $103.3 \pm 2.5$ & $27.4 \pm 1.0^{*}$ & $99.9 \pm 1.3$ & $52.2 \pm 1.1^{* \dagger}$ \\
$\mathrm{Cr}$ & $41.8 \pm 2.5$ & $117.7 \pm 1.0^{*}$ & $45.2 \pm 1.3$ & $92.9 \pm 1.1^{* \dagger}$ \\
$\mathrm{PCr}+\mathrm{Cr}$ & $143.7 \pm 3.1$ & $141.5 \pm 2.2$ & $146.7 \pm 4.2$ & $142.7 \pm 3.0$ \\
\hline
\end{tabular}

\section{Table 2}

Muscle content of glycogen and glycolytic intermediates at rest and following stimulation. Values are means \pm SE and metabolites expressed as mmol kg-1 dry weight, $\mathrm{n}=8$ for all conditions. Glycogenolytic flux was calculated from $\Delta \mathrm{GI}+0.5(\Delta \mathrm{Lac}+\Delta \mathrm{Pyr})$, where GI is the sum of glucose, G-6-P, G-1-P and F-6-P and $\Delta \mathrm{Lac}$ is the sum of Lac accumulated in the muscle and Lac released to the buffer. ${ }^{*}$ Significant different from resting value. ${ }^{\dagger}$ Significantly different from Con.

\begin{tabular}{lcccc}
\hline & $\begin{array}{c}\text { Con } \\
\text { non-stimulated }\end{array}$ & $\begin{array}{c}\text { Con } \\
\text { stimulated }\end{array}$ & $\begin{array}{c}\text { BTS } \\
\text { non- } \\
\text { stimulated }\end{array}$ & $\begin{array}{c}\text { BTS } \\
\text { stimulated }\end{array}$ \\
\cline { 2 - 5 } Glycogen & $120.8 \pm 3.6$ & $94.5 \pm 3.5^{*}$ & $111.2 \pm 4.3$ & $97.6 \pm 4.6^{*}$ \\
GI & $1.8 \pm 0.1$ & $4.2 \pm 0.6^{*}$ & $2.4 \pm 0.2$ & $3.6 \pm 0.4^{* \dagger}$ \\
Glucose & $1.2 \pm 0.1$ & $1.3 \pm 0.2^{*}$ & $1.6 \pm 0.1$ & $1.5 \pm 0.2^{*}$ \\
G-6-P & $0.5 \pm 0.04$ & $2.6 \pm 0.4^{*}$ & $0.7 \pm 0.1$ & $1.8 \pm 0.1^{*}$ \\
G-1-P & $0.01 \pm 0.01$ & $0.01 \pm 0.01$ & $0.03 \pm 0.01$ & $0.03 \pm 0.01$ \\
F-6-P $P$ Pyr & $0.04 \pm 0.02$ & $0.24 \pm 0.05^{*}$ & $0.08 \pm 0.02$ & $0.23 \pm 0.04^{*}$ \\
Lac, muscle & $0.3 \pm 0.02$ & $1.1 \pm 0.05^{*}$ & $0.3 \pm 0.02$ & $0.8 \pm 0.07^{*}$ \\
Lac, released & $5.3 \pm 0.5$ & $47.8 \pm 1.1^{*}$ & $4.5 \pm 0.3$ & $26.3 \pm 2.4^{* \dagger}$ \\
Muscle pH & $0.7 \pm 0.2$ & $4.6 \pm 0.4^{*}$ & $1.9 \pm 0.04$ & $4.7 \pm 0.5^{*}$ \\
$\Delta$ & $7.0 \pm 0.01$ & $6.8 \pm 0.01^{*}$ & $7.0 \pm 0.01$ & $6.9 \pm 0.01^{*}$ \\
Glycogen & - & $26.3 \pm 0.9$ & - & $13.6 \pm 1.4^{*}$ \\
Calculated & & & & $13.7 \pm 1.4^{*}$ \\
glycogenolytic flux & - & $26.0 \pm 0.9$ & - & \\
\hline
\end{tabular}




\section{TABLE 3}

ATP-turnover rates during stimulation. Values are means \pm SE. ATP-turnover data are given in mmol ATP, calculated from the formula; $-\Delta \mathrm{PCr}-(2 \times \Delta \mathrm{ATP}-\triangle \mathrm{ADP})+1,5 \times(\Delta \mathrm{Lac}+$ $\Delta \mathrm{Pyr})$, where $\Delta$ is the difference between stimulated and corresponding non-stimulated contralateral muscle. $\mathrm{n}=8$ for both Con and BTS muscles. ${ }^{\dagger}$ Significantly different from Con.

\begin{tabular}{|c|c|c|}
\hline & Con & BTS \\
\hline $\begin{array}{ll}\text { ATP-turnover } & \text { mmol ATP kg-1 } \mathrm{dw} \\
& \text { mmol ATP kg-1 } \mathrm{dw} \mathrm{s}^{-1}\end{array}$ & $\begin{array}{r}147.7 \pm 3.0 \\
32.6 \pm 2.4\end{array}$ & $\begin{array}{l}86.3 \pm 2.5 \\
18.4 \pm 0.5\end{array}$ \\
\hline $\begin{array}{l}\qquad \text { mmol ATP kg }{ }^{-1} \mathrm{dw} \cdot \mathrm{Ns}^{-1} \\
\text { ATP derived from PCr }(\% \text { of total }) \\
\text { ATP derived from glycolysis }(\% \text { of total })\end{array}$ & $\begin{array}{l}46.5 \pm 3.4 \\
51.4 \pm 0.8 \\
47.9 \pm 0.7\end{array}$ & $\begin{array}{l}73.6 \pm 2.7 \\
55.8 \pm 2.6 \\
43.2 \pm 2.4\end{array}$ \\
\hline
\end{tabular}




\section{FIGURE LEGENDS}

Figure 1. Effect of BTS on force production during fatiguing stimulation. Muscles were stimulated using supramaximal $60 \mathrm{~Hz}, 0.2 \mathrm{~s}$ pulses every $4 \mathrm{~s}$, in the absence (controls, •) or presence of BTS $(\boldsymbol{\Delta})$. BTS muscles were incubated in $50 \mu \mathrm{M}$ BTS for $90 \mathrm{~min}$ prior to fatiguing stimulation. Control muscles were stimulated until force was reduced to $70 \%$ of initial force. BTS muscles were stimulated for the time corresponding to the average time of stimulation for control muscles. Data points correspond to mean \pm SEM, $n=5-8$ and 8 for control and BTS muscles, respectively, and are normalised to the initial force produced 90 min prior to fatiguing stimulation. * represent statistical significant difference from initial force.

Figure 2. Glycolytic- and glycogenolytic rate. Glycolytic (A) and glycogenolytic (B) rates stimulation of Con and BTS muscles with supramaximal $60 \mathrm{~Hz}, 0.2 \mathrm{~s}$ pulses every $4 \mathrm{~s}$. BTS muscles were incubated with the cross-bridge cycle inhibitor BTS for $90 \mathrm{~min}$ prior to stimulation. $\mathrm{n}=8$ for Con and BTS muscles. Glycolytic flux is calculated by; $(\Delta \mathrm{Lac}+$ $\Delta$ pyr $) / 2$, and glycogenolytic flux is estimated from direct measures of the difference in muscle glycogen content at rest and following stimulation. Rates are given per stimulation period. $\dagger$ Significantly different from Con.

Figure 3. Comparison of muscle PCr content to that of lactate. Values at rest (Con, $\mathbf{m}$; BTS, $\bullet$; $30{ }^{\circ} \mathrm{C}$ incubation $10 \mathrm{~min}, \boldsymbol{\Delta}$ ) and stimulated (Con, $\square$; BTS, ०; half work, $\Delta$ ). The relationship between PCr and lactate is curvilineary and can be described by the two phase exponential decay equation: $\mathrm{PCr}=59.6 \mathrm{e}^{-0.035 \mathrm{Lac}}+54.8 \mathrm{e}^{-0.035 \mathrm{Lac}}$ (derived from Con rest, Con stimulated and half work data), $\mathrm{r}^{2}=0.95$.

Figure 4. Relation between force-time integral and ATP utilization. The linear relationship between ATP utilization and the force time integral (isometric "work") with 95\% confidence interval. The relation is best fit by the equation: ATP utilization $=58.7+25.0 *$ force time integral $\left(\mathrm{R}^{2}=0.86\right)$. The intercept denotes non-contractile energy utilization and was 59 (4374) mmol ATP and total energy utilization were on average $146 \mathrm{mmol} \mathrm{ATP} \mathrm{kg}{ }^{-1} \mathrm{dm}$. Thus, under our conditions of intermittent static contractions for 90s, non-contractile energy utilization on average accounted for $40 \%(29-51 \%)$ and the cross-bridge cycling corresponds to $60 \%(49-71 \%)$ of the total energy utilization. 


\section{Figure 1}

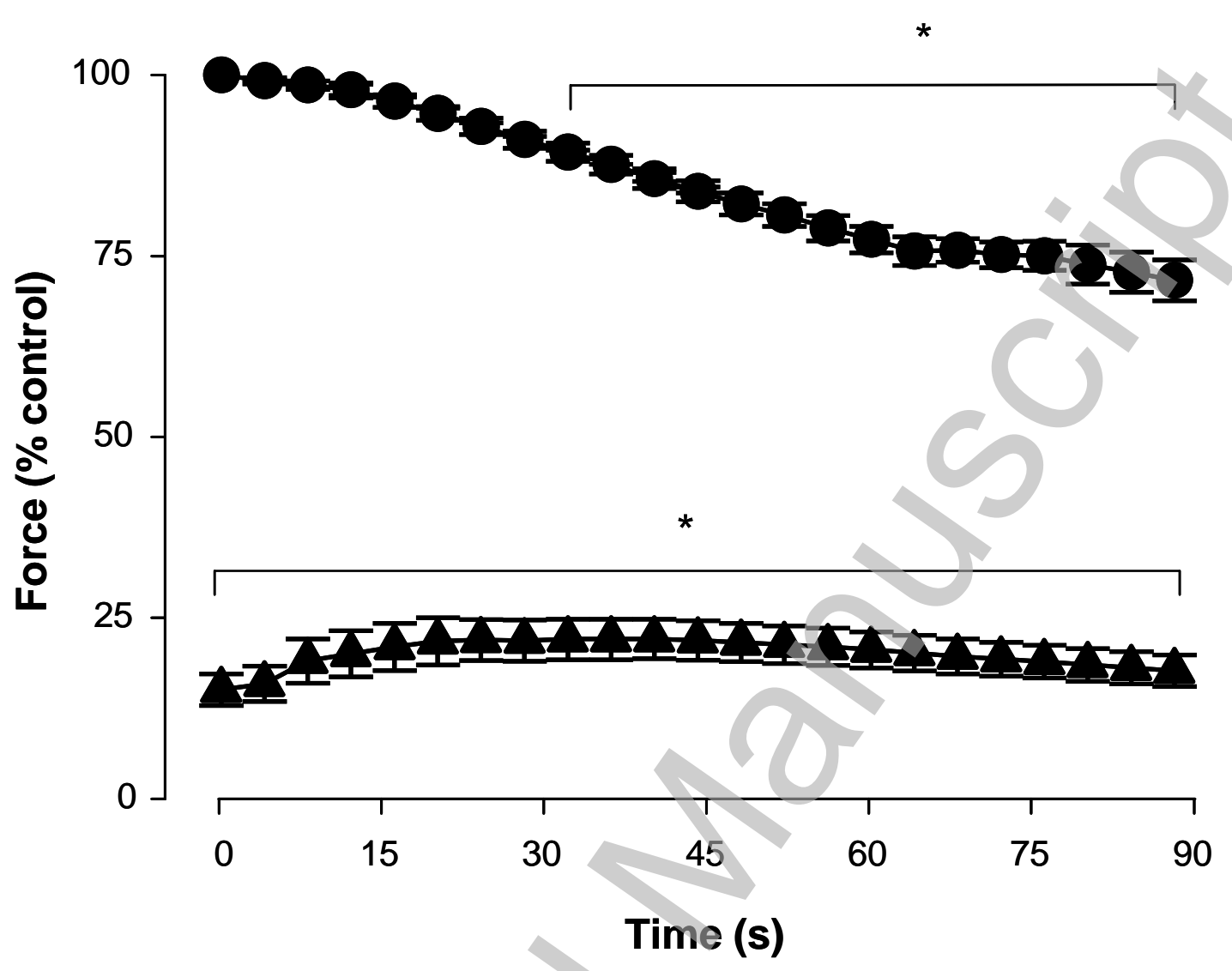

Figure 1. Effect of BTS on force production during fatiguing stimulation. Muscles were stimulated using supramaximal $60 \mathrm{~Hz}, 0.2 \mathrm{~s}$ pulses every $4 \mathrm{~s}$, in the absence (controls, •) or presence of BTS $(\boldsymbol{\Delta})$. BTS muscles were incubated in $50 \mu \mathrm{M}$ BTS for $90 \mathrm{~min}$ prior to fatiguing stimulation. Control muscles were stimulated until force was reduced to $70 \%$ of initial force. BTS muscles were stimulated for the time corresponding to the average time of stimulation for control muscles. Data points correspond to mean \pm SEM, $n=5-8$ and 8 for control and BTS muscles, respectively, and are normalised to the initial force produced 90 min prior to fatiguing stimulation. * represent statistical significant difference from initial force. 
Figure 2

A glycolytic rate

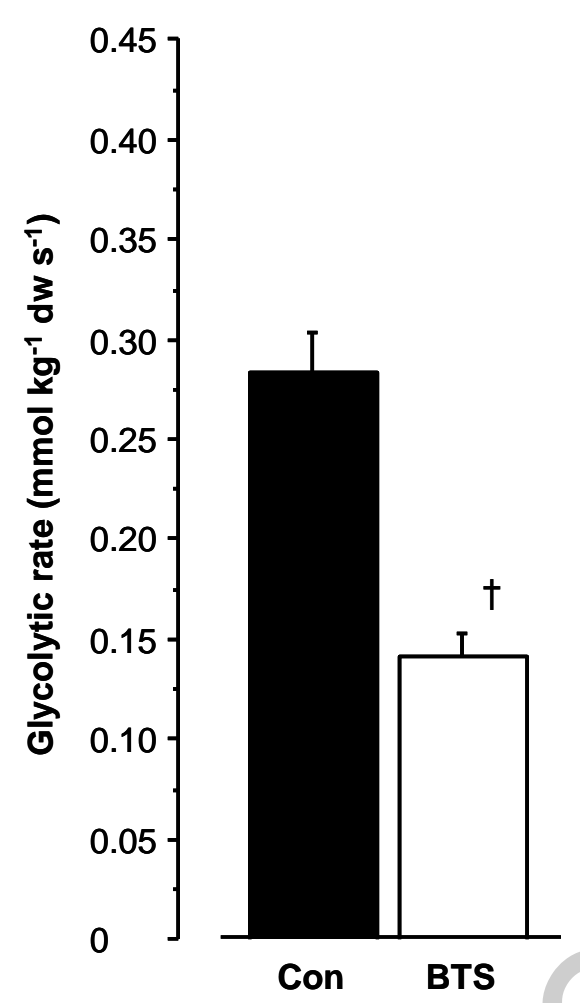

B Glycogenolytic rate

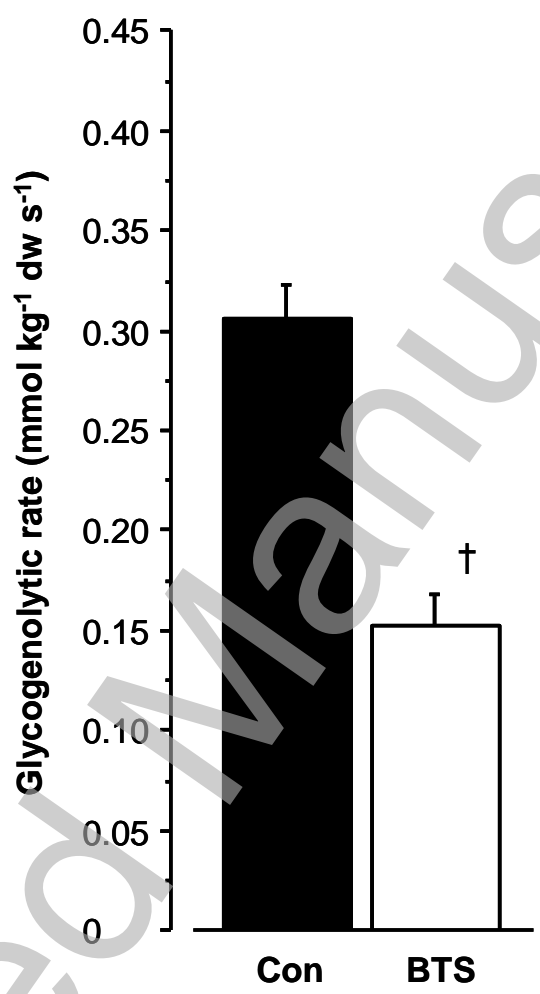

Figure 2. Glycolytic- and glycogenolytic rate. Glycolytic (A) and glycogenolytic (B) rates during $88 \mathrm{~s}$ (Con) and $90 \mathrm{~s}$ (BTS) stimulation with supramaximal $60 \mathrm{~Hz}, 0.2 \mathrm{~s}$ pulses every $4 \mathrm{~s}$. BTS muscles were incubated with the cross-bridge cycle inhibitor BTS for $90 \mathrm{~min} . \mathrm{n}=8$ for Con and BTS muscles. Glycolysis is calculated by; $(\Delta \mathrm{Lac}+\Delta \mathrm{pyr}) / 2$, and glycogenolysis was estimated from direct measures of the difference in muscle glycogen content at rest and following stimulation. Rates are given per stimulation period. $†$ Significantly different from Con. 


\section{Figure 3}

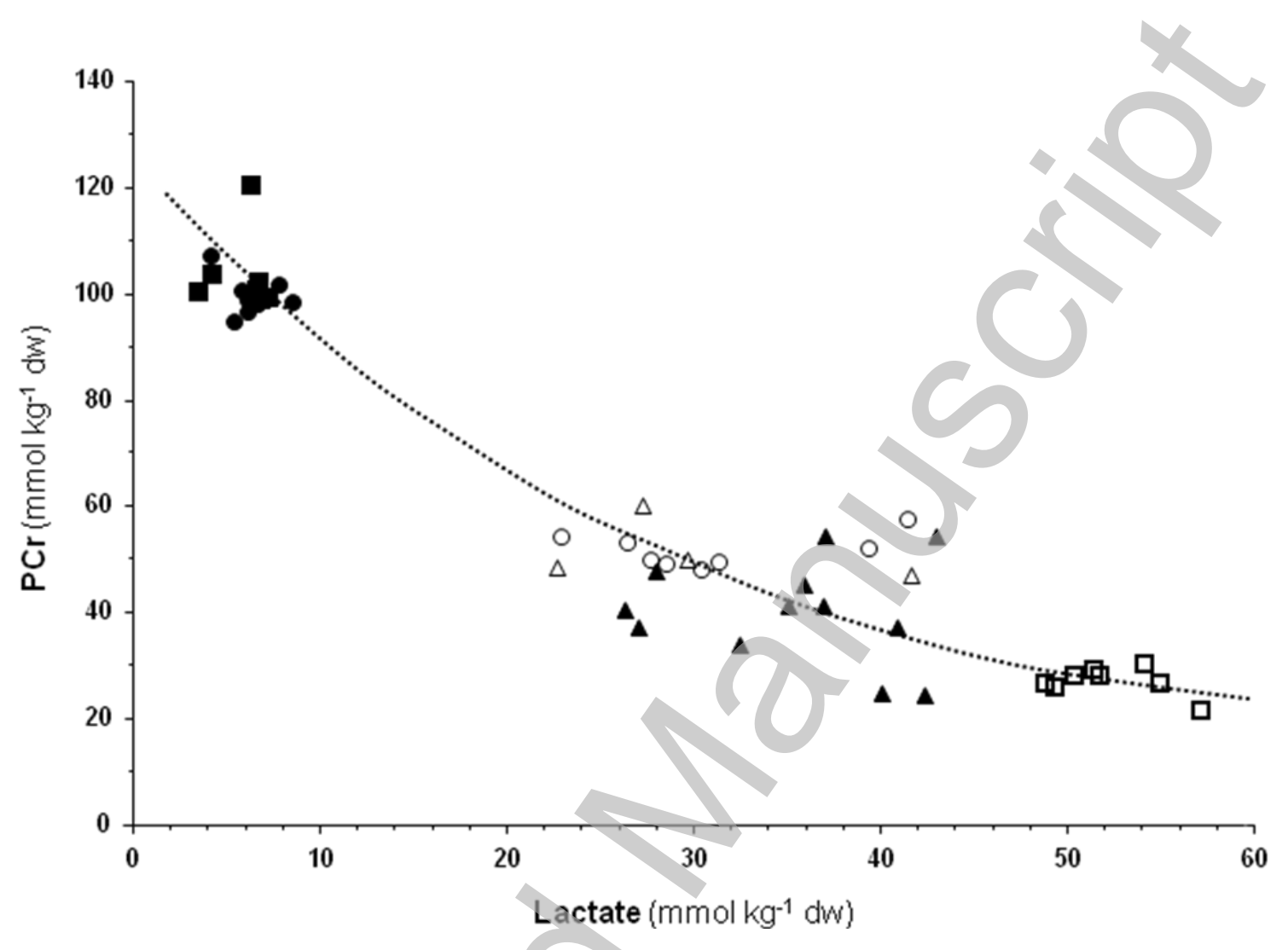

Figure 3. Comparison of muscle PCr content to that of lactate. Values at rest (Con, $\mathbf{m}$; BTS, •; $30^{\circ} \mathrm{C}$ incubation $10 \mathrm{~min}, \boldsymbol{\Delta}$ ) and stimulated (Con, $\square$; BTS, $\circ$; half work, $\Delta$ ). The relationship between $\mathrm{PCr}$ and lactate is curvilineary and can be described by the two phase exponential decay equation: $\mathrm{PCr}=59.6 \mathrm{e}^{-0.035 \mathrm{Lac}}+54.8 \mathrm{e}^{-0.035 \mathrm{Lac}}$ (derived from Con rest, Con stimulated and half work data), $\mathrm{r}^{2}=0.95$. 


\section{Figure 4}

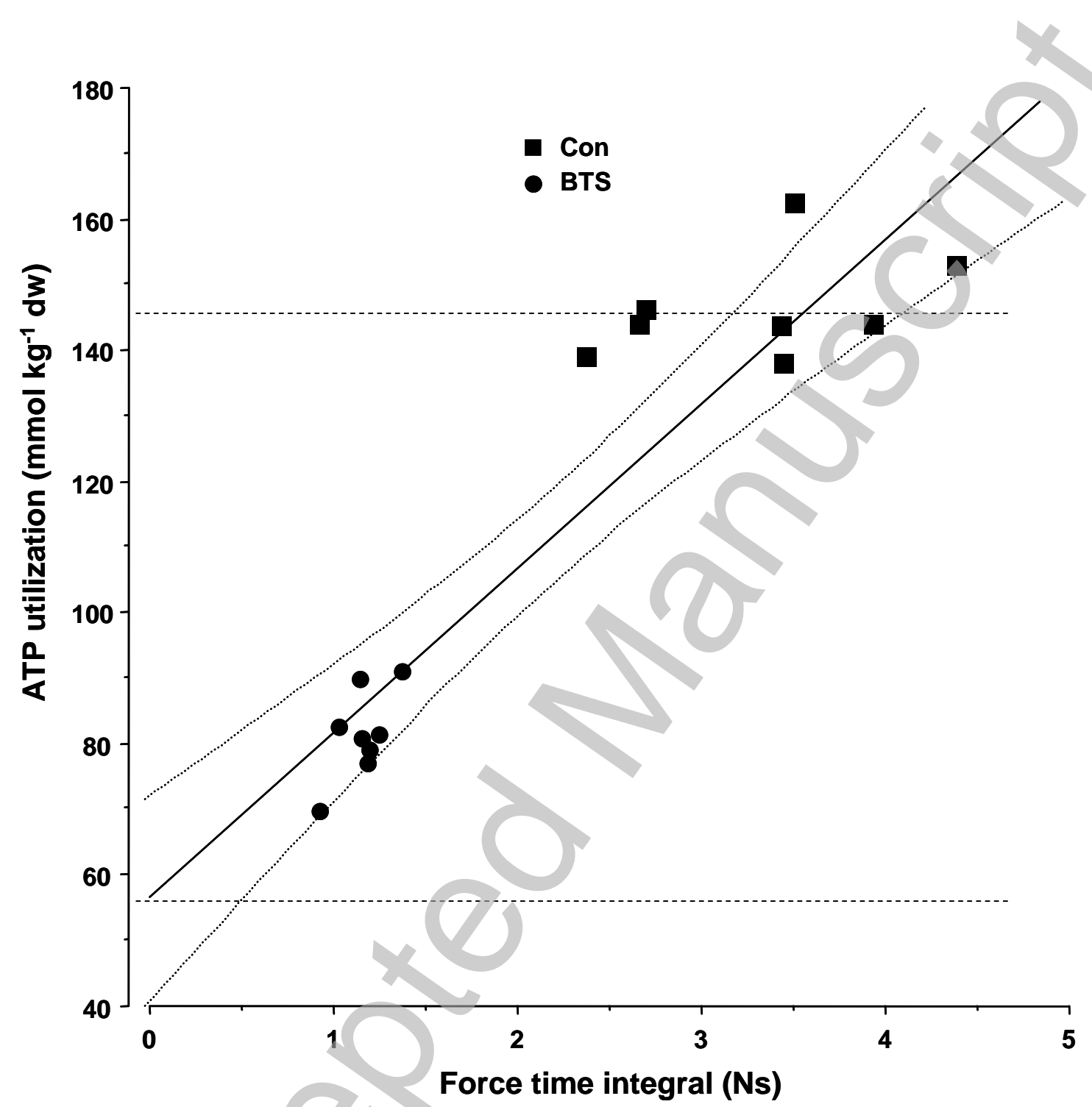

Figure 4._Relation between force-time integral and ATP utilization. The linear relationship between ATP utilization and the force time integral (isometric "work") with 95\% confidence interval. The relation is best fit by the equation: ATP utilization $=58.7+25.0 *$ force time integral $\left(R^{2}=0.86\right)$. The intercept denotes non-contractile energy utilization and was $59(43-$ 74) mmol ATP and total energy utilization were on average $146 \mathrm{mmol} \mathrm{ATP} \mathrm{kg}{ }^{-1} \mathrm{dm}$. Thus, under our conditions of intermittent static contractions for 90s, non-contractile energy utilization on average accounted for $40 \%(29-51 \%)$ and the cross-bridge cycling corresponds to $60 \%(49-71 \%)$ of the total energy utilization. 